\title{
Annuntiatio Domini: Metaphoric conceptualization and gesture analysis in painted representations of the Annunciation
}

\author{
Fabio Indìo Massimo Poppi \& Peter Kravanja
}

\begin{abstract}
In this article, we analyze ten artistic paintings of the Annunciation ranging from the XV century to the XX century in order to describe how the interaction between pictorially represented gestures and other pictorial elements allows them to convey more abstract meanings. Applying a historical approach to the gestures expressed by Mary, we show how - despite the different artistic approaches and sensitivities - her hand gestures always have a primary importance in conveying the meanings of PRUDENCE, CAUTION, FEAR, SURPRISE, CONCERN and GRATITUDE. We show how such gestures can be related to ordinary linguistic expressions that present analogous meanings. It is thus shown how gestural metaphor may interact with other modalities in pictorial representations.
\end{abstract}

Keywords: annunciation; art; conceptual metaphor; metaphoric gesture; painting; pictorial metaphor

\section{Introduction}

Since conceptual metaphors began to be investigated beyond linguistic manifestations (see, e.g., Gibbs, 2008), research has encountered new challenges. On the one hand, metaphors are analyzed in terms of pictorial stimuli (Forceville, 2006), gesture (Cienki and Müller, 2008), music (Zbikowski, 2008) and multimodal representations such as film (Coëgnarts and Kravanja, 2012a; 2012b). On the other hand, research tends to consider these representations without considering the interaction between modalities. ${ }^{1}$ In addition, although non-linguistic modalities occupy a central role in research, only a few studies have taken into account how metaphors are conveyed in artistic paintings.

To begin addressing this gap, we investigate ten paintings of the Annunciation the Gospel event regarding the announcement by the Angel Gabriel to Virgin Mary that she would conceive and become the mother of Jesus, the Son of God, marking his Incarnation - ranging from the $\mathrm{XV}$ century to the $\mathrm{XX}$ century. Our aim is to discuss how Mary's metaphoric gestures are represented in pictorial terms and how the interaction between these representations relates to other pictorial elements and allows them to convey and represent several spiritual and emotional meanings. In methodological terms, we discuss the Annunciation regarding pictorial metaphors and gestural components.

We also indicate conceptual relationships by identifying some ordinary expressions in English and Italian in order to show how the pictorial elements and gestures reflect the linguistic level as well. The decision to analyze paintings of the Annunciation is based on the wish to consider the role of hand gestures and their potential meanings and how they can be represented across different historical periods and artistic styles. In this way, we aim to apply a historical approach to a non-linguistic modality such as paintings, which has rarely been addressed in metaphor studies.

\footnotetext{
${ }^{1}$ The notion of modality follows Forceville's tradition and terminology. As Coëgnarts and Kravanja (2012b, p. 101) claim: "The modality deals with the question as to how the metaphorical thought (structural - conceptual or image) manifest itself to our senses. With no claim to exhaustiveness Forceville (2009: 23-24) categorizes nine different modalities: pictorial signs, written signs, spoken signs, gestures, sounds, music, smells, tastes and touch."
} 
Public Journal of Semiotics 8 (1)

\section{Theoretical background}

Scholars such as Black (1955), Ortony (1979) and Lakoff and Johnson (1980) have developed theories of metaphor not merely as a linguistic phenomenon, but as a process playing a central role in a series of cognitive operations. At the base of these operations, metaphor allows the expression and interpretation of a more abstract and unusual element (usually called the target) in terms of a more concrete and familiar one (the source). As recent contributions have shown (see, e.g., Gibbs, 2008), metaphor operates in pictorial contexts such as billboards and paper advertising (Forceville, 2006), gesture (Cienki and Müller, 2008), music (Zbikowski, 2008; Poppi, in prep.) and multimodal representations such as film and commercials (Forceville and Urios-Aparisi, 2009; Coëgnarts and Kravanja, 2012a, 2012b).

Regarding the study of conceptual metaphor in relation to non-linguistic modalities, we can identify two challenges. First, if we consider metaphor in pictorial modalities, research has been oriented towards describing the semiotic relationships that occur between conceptual domains (El Rafaie, 2003; Forceville, 2008). Although some contributions have used large corpora of pictorial representations such as advertisements in order to understand the distribution of conceptual operations and the use of modal cues (e.g., Pérez-Sobrino, 2016), what has not been considered is how a certain pictorial representation is structured by conceptual metaphors in different historical periods. While this approach has been applied in linguistic metaphor analysis (Musolff, 2004), where, for instance, a particular conceptualization such as the NATION IS A BODY metaphor is explored through its application in different historical contexts, a similar perspective has been almost completely neglected in pictorial modalities.

Second, research that addresses non-linguistic modalities such as image or gesture, tends to consider these representations without considering the interaction between modalities. Although Forceville (2009, p. 24) defines multimodal metaphor as "a metaphor whose target and source are each represented exclusively or predominantly" in different modalities, very few contributions take into account how two modalities interact in a specific way. Research in multimodal representations such as film and TV commercials (Forceville and Urios-Aparisi, 2009) is generally oriented to identify source and target relationships without investigating how the modalities involved in the representation interact. If we exclude the notion of "verbo-pictorial" metaphor (Forceville, 1996), which describes how an image can interact with a textual component to produce a metaphor, interaction between modalities has generally been neglected. Additionally, theoretical frameworks that address how gestures can reveal metaphoric conceptualizations (Cienki and Müller, 2008) have rarely referred to other modalities such as pictorial stimuli. Certain approaches have analyzed gestures within filmic representations (Kappelhoff and Müller, 2011), but film seems to be simply the context within which to discuss gestures rather than a modality to consider in interaction with gesture itself (see Bonnell, 1997, for an exception). We rather suggest that the combination of depicted gestures and other pictorial elements represents an example of multimodal metaphor that requires to be analyzed as such in a genre such as paintings.

From these premises, this article takes a historical approach to pictorial metaphor by addressing which conceptual metaphors are conveyed across different periods in depictions of the Annunciation, one of the most common subjects in the history of religious 
paintings. For this reason, we consider ten artistic paintings of the Annunciation ranging from the XV century to the XX century. In addition, we consider how pictorially represented gestures and other pictorial elements express conceptual metaphors which are conveyed by the paintings of the Annunciation. The decision to use artistic paintings is based on the lack of contributions regarding this genre in metaphor studies, since most of the research is generally focused on magazine and billboard advertisements (Phillips and McQuarrie, 2004; Van Mulken et al., 2010) and on entertainment material such as cartoons and comic-strips (El Refaie, 2003; Schilperoord and Maes, 2009; Bounegru and Forceville, 2011). The present article makes a further contribution to the question of how artistic paintings can be interpreted in the light of metaphoric conceptualization.

\section{Context of analysis}

\subsection{Pictorial metaphor and metaphoric gesture}

We regard a pictorial metaphor as a juxtaposed or merged pictorial depiction of two different objects or actions designed to encourage viewers to infer an implicit conceptual link, without the involvement of other modalities such as spoken or written words (see footnote 1). Regarding the distinction between the two domains, we agree with those approaches that tend to identify target and source domains by starting from the abstractness or concreteness, respectively, of the domains themselves. Specifically, the target domain is the more abstract and unusual element that interacts with a more concrete and familiar one (the source) in various ways (Forceville, 2008). Further we agree with the definition of Cienki and Müller (2008, p.5): "we are calling metaphoric gestures the ones which have the potential to engage an active cross-domain mapping, that is - the cognitive process of understanding something in terms of something else". For instance, the use of the right arm extended forward, with the hand also extended, pointing forward with the index finger, may stand for FUTURE and PROGRESS, in line with the mapping FUTURE IS FORWARD (Kövecses, 2010).

\subsection{Annunciation and iconography}

As mentioned in the Introduction, the Annunciation is the Biblical event in which Archangel Gabriel announces to Mary that she will become the mother of Jesus, the Son of God. The depictions of the Annunciation going back to early Christianity up to the 4th century with the fresco of the Annunciation in the Priscilla catacomb in Rome, contain some precise representational elements. Apart from the figure of the Mary, the Annunciation also presents the figure of Archangel Gabriel, either in human form or in more abstract terms such as light, iconographically standing on the left, facing the Virgin, who is generally seated or kneeling, at least in later depictions (see Grootenboer, 2007). The physical space in which the scene is placed has widely varied in art history, moving from indefinite spaces to realistic settings until assuming more surrealistic connotations in modern art representations. 


\section{Material and methods}

\subsection{Material}

Since the Annunciation is one of the most iconic events of the Bible, it appears in the work of almost all of the great masters, especially during the Middle Ages and the Renaissance. In order to base our analysis on a variety of examples, we have decided to use ten paintings ranging from the XV century to the $\mathrm{XX}$ century with the aim of covering this vast historical interval as homogeneously as possible and in a way that reflects the different artistic sensitivities that have occurred over the centuries. In this way, we aim to show how pictorial and gestural metaphors may vary across different historical sensitivities and artistic approaches. The details of the artistic paintings are shown in Table 1.

Table 1. The sample of paintings analyzed

\begin{tabular}{|c|c|c|c|}
\hline Figure & Title & Author & Year \\
\hline 1 & Annunciation & Beato Angelico & 1435 \\
\hline 2 & Virgin Annunciation & Antonello da Messina & 1476 \\
\hline 3 & Recanati Annunciation & Lorenzo Lotto & 1534 \\
\hline 4 & Annunciation & Caravaggio & 1608 \\
\hline 5 & The Annunciation & Salomon Koninck & 1655 \\
\hline 6 & Annunciation & Francisco Goya & 1785 \\
\hline 7 & Annunciation & Henry Ossawa Tanner & 1898 \\
\hline 8 & Annunciation & Luc Oliver Merson & 1908 \\
\hline 9 & Annunciation & $\begin{array}{l}\text { John William } \\
\text { Waterhouse }\end{array}$ & 1914 \\
\hline 10 & The Painful Annunciation & $\begin{array}{l}\text { Léon Henri Marie } \\
\text { Frédéric }\end{array}$ & 1927 \\
\hline
\end{tabular}

\subsection{Methods}

In methodological terms, the paintings were analyzed in terms of pictorial metaphors with a particular emphasis on the pictorial representation of gesture. At various points in the analysis, we intentionally introduce a few linguistic examples from English and Italian purely for familiarization purposes. In order to present an analysis also supported by linguistic conceptualizations, we focus on those metaphors that have been mainly identified in the Italian metaphor databases (Alonge, 2006) and Goatly's Metalude (2005) and Kövecses (2010) for ordinary English expressions. In addition, we focus the metaphoric 
gesture analysis mainly on the gestures expressed by Mary. In our discussion, the usual notation for metaphorical representation (X IS Y) follows the general criterion of considering the less concrete/familiar/specified entity (Y) as expressed by the depicted gesture as the target $(\mathrm{X})$.

Since the Annunciation paintings have a clear figurative intention, most of the examples we discuss can result in contextual metaphors. Specifically, as the Annunciation necessarily represents Mary's state of mind (target) by way of her gestures (source), the role of the pictorial context is functional to the identification of all those less concrete/familiar/specified elements that characterize the abstract domains. In this regard, we identify which of Mary's gestures can be associated with the less concrete elements that are suggested by the pictorial context of the painting. In contrast with other studies that focus on metaphoric gesture, it should be noticed that our approach differs from influential contributions such as Cienki (2016a, 2016b). While these studies address gesture identification according to metaphors within dynamic contexts (e.g., video and animation), this study takes into account gesture within static representations like paintings. Therefore, we simply focus on which gestures are portrayed and how they can be associated with less concrete elements.

We use a general perspective on metaphor, as a notion where a communicator refers to X using the more specific Y (Hanks, 2006; Veale, 2013). In this sense, metaphor assumes the role of a higher-order term that includes other conceptual processes, such as similes and analogies (Silvia and Beaty, 2012). Regarding the relation between metaphor and metonymy (see Turner and Fauconnier, 2003; Barnden, 2010; Barcelona, 2011), since many metaphors seem to be based on metonymies (usually defined as withindomain mappings), and it is often difficult to define the borders of conceptual domains, we adopt an encompassing view of metaphor as a phenomenon that refers to a more abstract element $\mathrm{X}$ using a more concrete element $\mathrm{Y}$ without claiming anything else about the relationship between the two elements. In line with Alfieri (2008), we consider that metaphors and metonymies represent two applications of the same process of conceiving and understanding an element in terms of another. Therefore, whereas some conceptualizations can be interpreted more closely in terms of metonymies, we would still prefer to refer to them as metaphors.

\section{Analysis}

Following a chronological pattern, we discuss each painting by introducing basic information about the content of the artwork and its style. Since artistic paintings require a deeper and more interpretative approach, we use as references the contributions of art critics and historians. In certain cases, the identification of pictorial metaphors and metaphoric gesture interpretations are also derived from these contributions.

Figure 1 shows Beato Angelico's Annunciation, which was painted around 1440 and today hangs in the Convent of San Marco in Florence, Italy. In structural terms, the scene is set outdoors where Gabriel visits Mary under a portico in a garden enclosed by a palisade. The setting is bare and essential, like the little room that opens behind the Virgin. In conceptual terms, a main pictorial and metaphoric gesture is conveyed both by the archangel and Mary. In announcing to Mary that she will become a mother, the two figures cross their arms over their stomachs in a metaphor that stands for the future birth of Jesus. As art historians have suggested (see Robb, 1936), the idea of MATERNITY is picto- 
rially associated with CROSSED ARMS ON THE STOMACH. The gesture of crossing arms stands both for embracing the womb space and for protecting God's gift. In this sense, the gesture represents not only the physical identification of the forthcoming motherhood and the experience but also its main function of protective caregiving. In addition, crossing arms around the body may be associated with sensations and feelings such as AFFECTION ("She holds me tightly") and PROTECTION ("I will shield you in my arms") that are rooted in the experience of MATERNITY itself and in the responsibility that Mary has in becoming the mother of God's son.

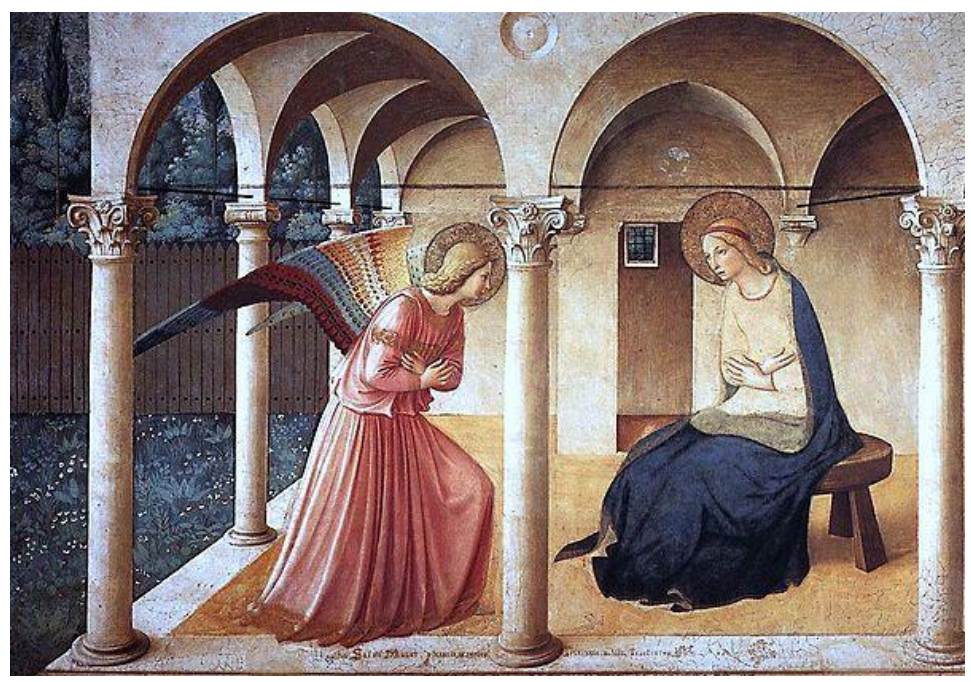

Figure 1. Annunciation - Beato Angelico, 1435

Virgin Annunciate, shown in Figure 2, by Antonello da Messina is an unusual representation of the Annunciation. Exhibited in the palazzo Abatellis in Palermo (Italy), the painting portrays Mary frontally - and not, as generally happens, from the left side and without the archangel being shown. What is more, while the Annunciation is always placed in an idealistic or figurative setting, here the subject is included within a plain dark scene that does not present any further decorative element, apart from a lectern and the book from which Mary reads. In representational terms, Mary reacts to the Annunciation of Gabriel with a gesture of her right hand that seems to want to stop the angel in his announcement (von Rohr Scaff, 2002). In addition, Mary draws the blue veil she wears across herself with her left hand in a gesture of protection. Since she reacts to the announcement with a certain prudence and caution, these two gestures can be interpreted as the following conceptual metaphors:

\section{PRUDENCE IS PUTTING ONE'S HAND FORWARD \\ PRUDENCE IS COVERING ONESELF WITH A CLOTH}

Despite the apparent complexity of this analysis, a similar conceptual construction is applied in major Romance languages. For example, Italian expressions such as mettere le mani avanti ('put ones hands forward') imply prudence, caution and guard against risk (Enciclopedia Treccani) whereas the verb abbottonarsi ('buttoning up') refers to the idea of closing in cautious reserve (Enciclopedia Treccani) 


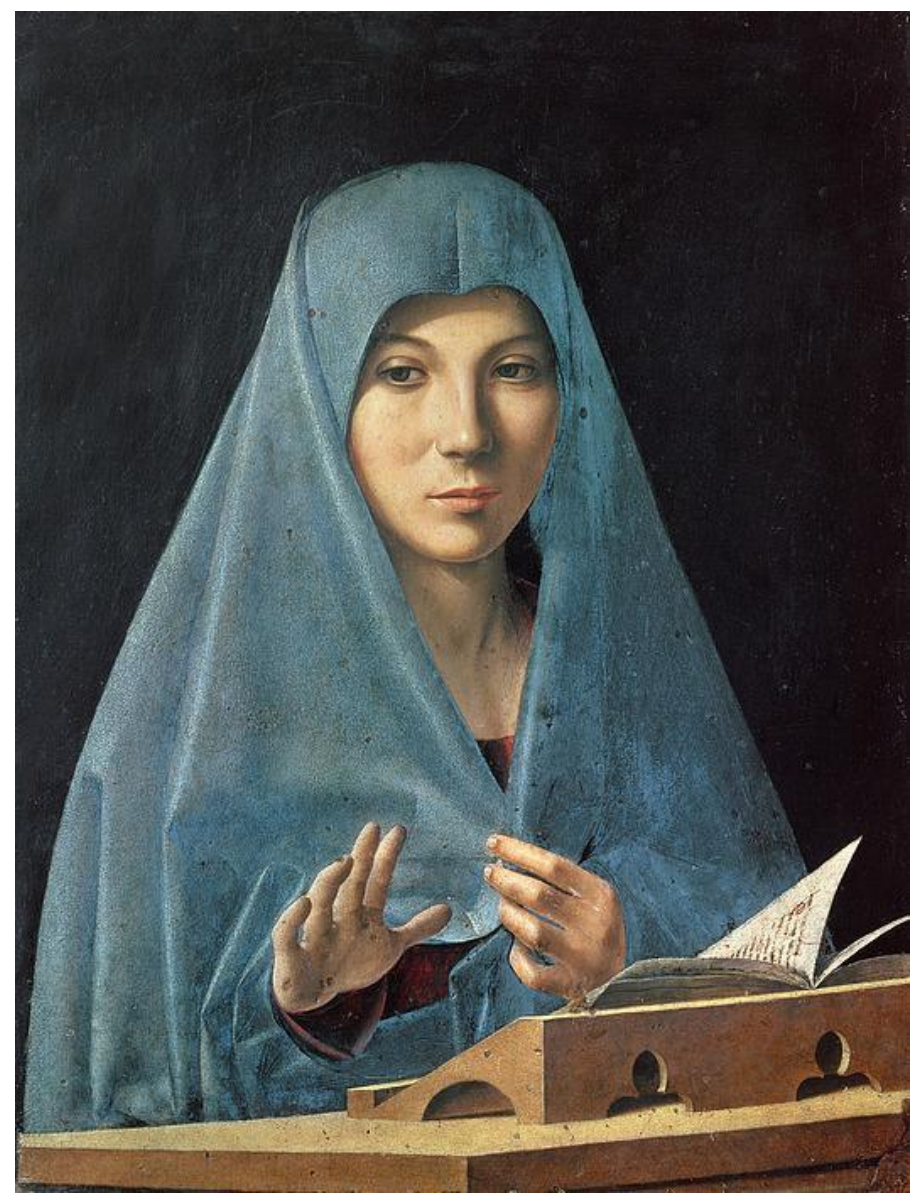

Figure 2. Virgin Annunciate - Antonello da Messina, 1476

Figure 3 shows the Recanati Annunciation by Lorenzo Lotto, painted around 1534 and housed in the Civic Museum of Villa Colloredo Mels, Recanati (Italy). As we can see, there are three elements of novelty. First, the painting includes a third subject in the representation: the Father God is depicted in a cloud in the top right. Second, Gabriel, generally depicted on the left, is here behind Mary. Finally, Mary's reaction to the arrival of the archangel does not express any symbolic sense of maternity, as in the Annunciation by Beato Angelico (Figure 1) nor any sort of caution as in the Virgin Annunciate by Antonello da Messina (Figure 2). Instead, the painting presents an association of surprise and even confusion. Mary's surprise is shown in her facial expression, by the shrug of her shoulders, and by her hand gestures, while it is further conveyed by the figure of the cat that literally flees, surprised at the arrival of the angel. In terms of metaphoric gestures, the CLASPED HANDS of God conventionally stand for a BLESSING and Gabriel's pointing up represents GOD, following the conceptual metaphor DIVINITY IS UP (Meier et al., 2007). Regarding Mary, the hand gesture seems to represent the attempt to distance herself from the Annunciation of her destiny, representing the metaphor SURPRISE IS RAISING THE PALMS (see Padgett, 2006). In this sense, the feelings of surprise that Mary shows are both related to the Annunciation itself (becoming the mother of Jesus, the Son of God) 
Public Journal of Semiotics 8 (1)

and to the process in which it is communicated (the angel comes from behind Mary, surprising her during her daily activities).

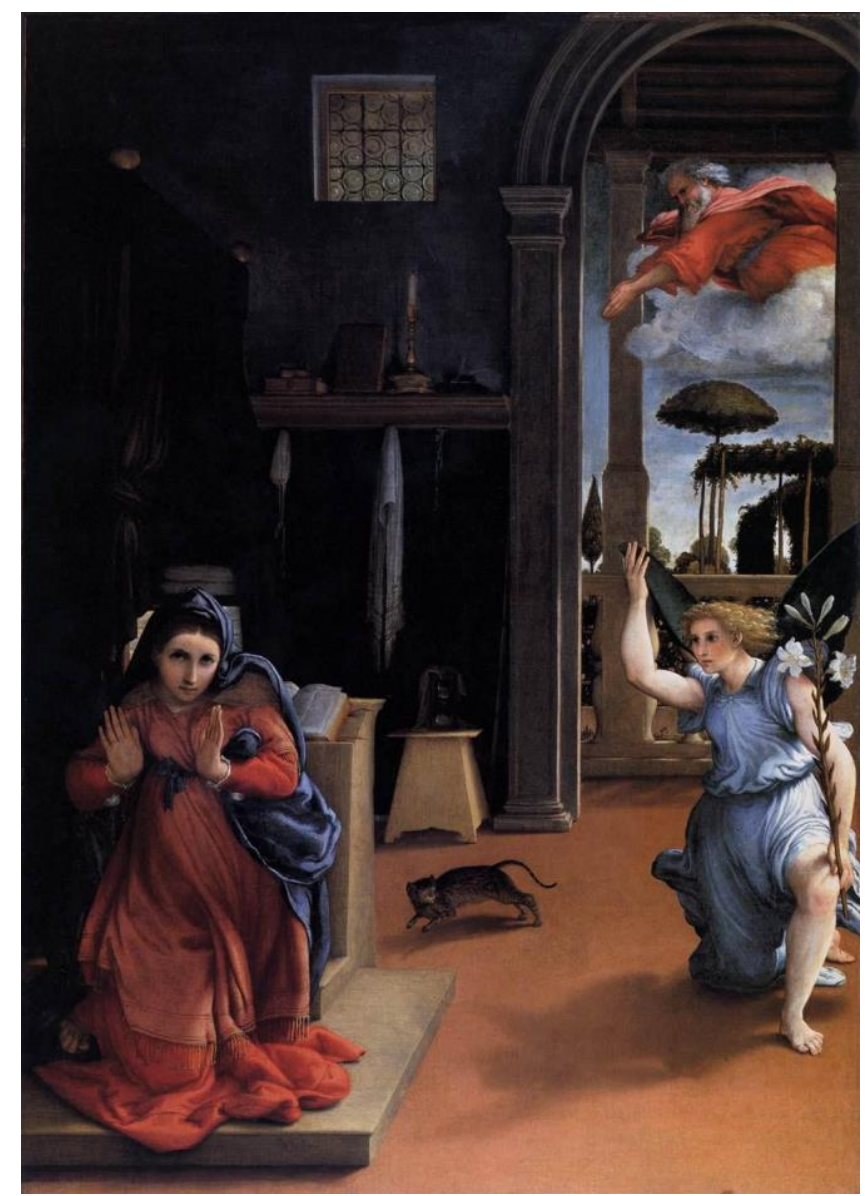

Figure 3. Recanati Annunciation - Lorenzo Lotto, 1534

Within the tradition of the Annunciation (two subjects, angel on the left), Caravaggio's work, shown in Figure 4, reinvented the relationship between Gabriel and Mary in a more dramatic and realistic scene. Finished around 1608 and housed in the Musée des Beaux-Arts de Nancy, France, Caravaggio's Annunciation changed the canonical representation of Mary and the archangel. While Gabriel usually stands or kneels in front of Mary, in this painting the Virgin shows a kind of obeisance to the heavenly figure. In addition, Caravaggio portrays the angel while he is still in flight and with his back turned to the viewer. In this perspective from above, the viewer has the sensation that Gabriel is greater than Mary. Although Caravaggio seems to present Mary in the background (note the bow and the proportions), the gestures that the Virgin shows highlight her emotional and spiritual dimension. Although, in terms of the position of her arms, Caravaggio's painting may be associated with Beato Angelico's Annunciation (Figure 1), here the arms are closer to the chest than to the belly in a dramatic attempt to show how MATERNITY is conceptualized in terms of ARMS CROSSED OVER THE CHEST. Also, in this case, the 
CROSSED ARMS stand for INTIMACY and AFFECTION, while the attention to the chest may be functional to representing Mary's heart, as an expression of her feelings ("'Her heart is filled with happiness", "She could no longer contain the joy in her heart").

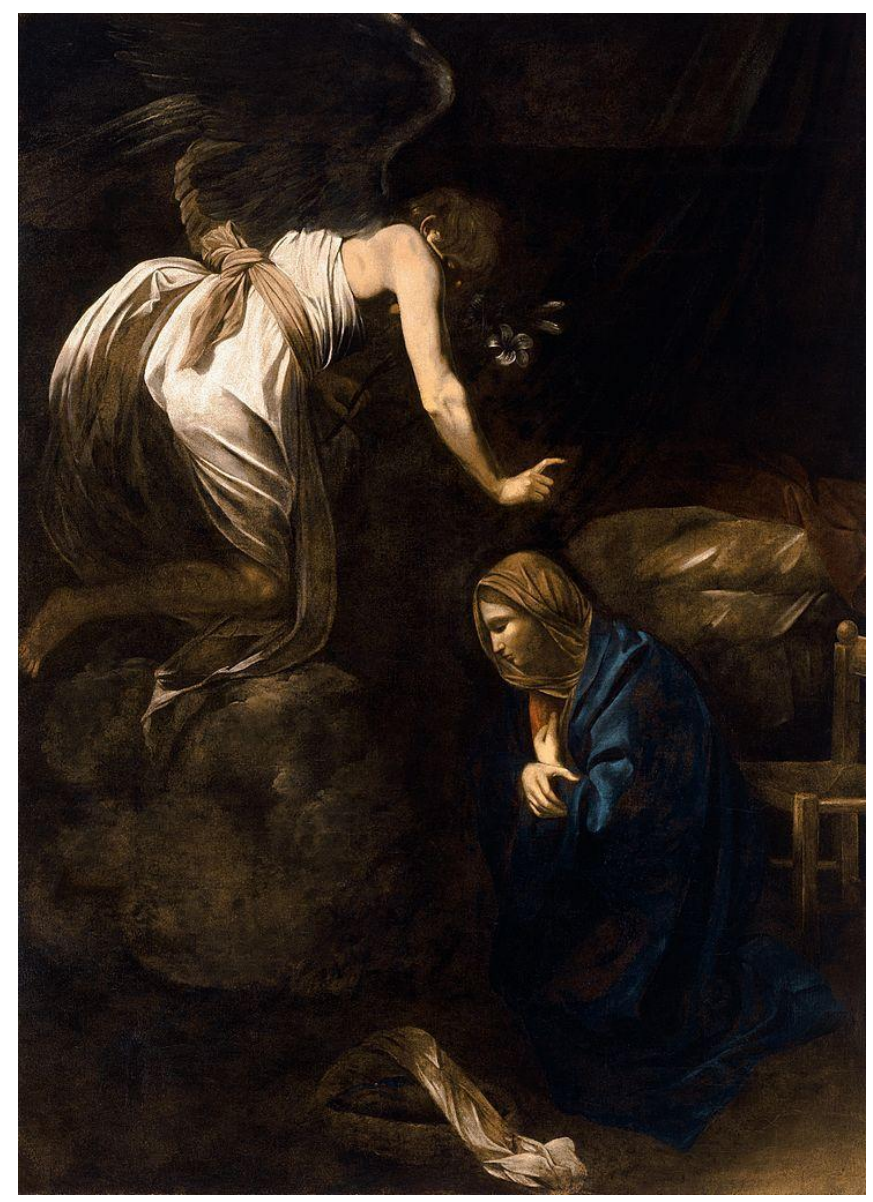

Figure 4. Annunciation - Caravaggio, 1608

Salomon Koninck's The Annunciation shown in Figure 5, created in 1655 and exhibited in the Albertina Museum in Vienna, Austria, seems to combine the tradition of Lorenzo Lotto with Caravaggio. As the painting shows, Mary is surprised by Gabriel's arrival behind her. In structural terms (e.g., realism), this painting is close to Caravaggio's Annunciation, for example in its depiction of Gabriel while he is still in flight and in its use of shadows and light. The element of surprise conveyed by Mary's reaction is analogous to the Recanati Annunciation (Figure 3).

In terms of metaphoric gesture, the SURPRISE that Mary shows is conveyed as RAISING THE PALMS as well, but two other elements contribute to make this scene particularly dramatic. First of all, while Lorenzo Lotto presents the facial expression of Mary as surprised, but still able to maintain a certain elegance and composure, in Koninck's The Annunciation the surprise expressed by Mary is more dramatic and realistic. In addition, while in the Recanati Annunciation Mary's surprised gaze is directed toward the viewer, here Mary confronts the angel and avoids including the spectator in the scene. As Padgett 
Public Journal of Semiotics 8 (1)

(2006, p. 195) claims, in Lorenzo Lotto's Annunciation "[Mary] appeals directly to us, her startled hands raised, as if to plead with us for an explanation". Koninck seems to convey instead a vision of the Annunciation something that brings forth an instinctive reaction, without the need for any "explanation". In this sense, the conceptualization of Mary's feelings in terms of RAISING THE PALMS is closer to the concept of FEAR than to a less dramatic experience of SURPRISE. As the combination of shadows and light suggests, the element of fear may be justified by the appearance of the archangel in the darkness of the room in which Mary is reading, while in the Recanati Annunciation Gabriel comes from an open space in the daylight.

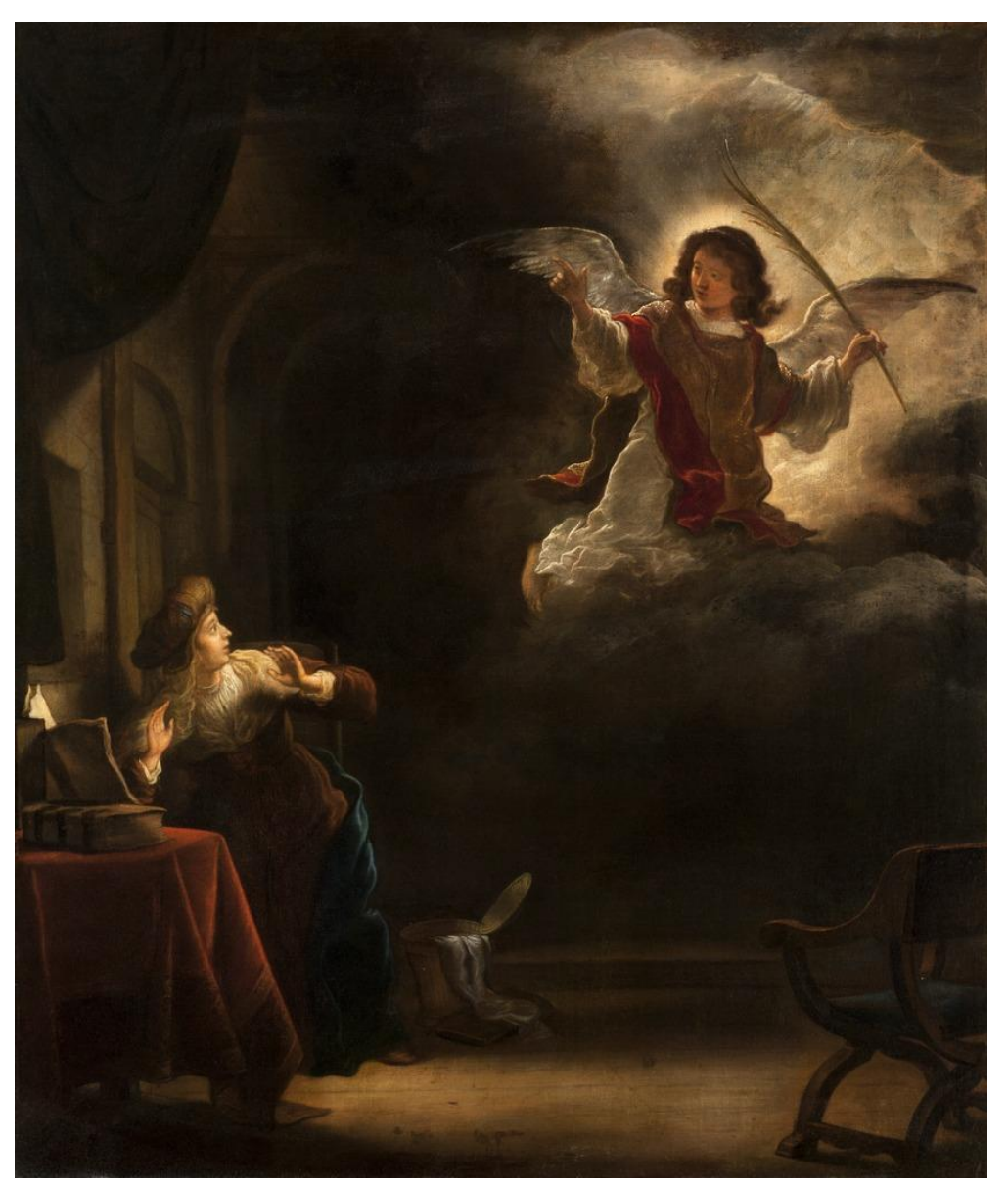

Figure 5. The Annunciation - Salomon Koninck, 1655

This Romantic example of the Annunciation made by Francisco Goya in 1785 shown in Figure 6 represents a further combination of pictorial and gestural metaphor. In structural terms, the painting presents Mary genuflecting in front of Gabriel who uses his index finger to point toward God, here portrayed as a beam of light. Note the presence of a white dove symbolizing the Holy Spirit. Here, in contrast with other paintings, the scene looks bright, quiet and harmonious, far from the drama and the fear of previous works. Mary seems to express her faith and hope in the decision communicated by Gabriel and 
her hands are functional to conveying similar meanings. Within the Christian tradition, CLASPED HANDS do not only represent the gesture of PRAYING, but they are also associated with further meanings such as SUBMISSION - especially if accompanied by genuflection - and GRATITUDE. Thus, in Goya's Annunciation, Mary agrees serenely to become the Mother of God and shows her dedication to this role.

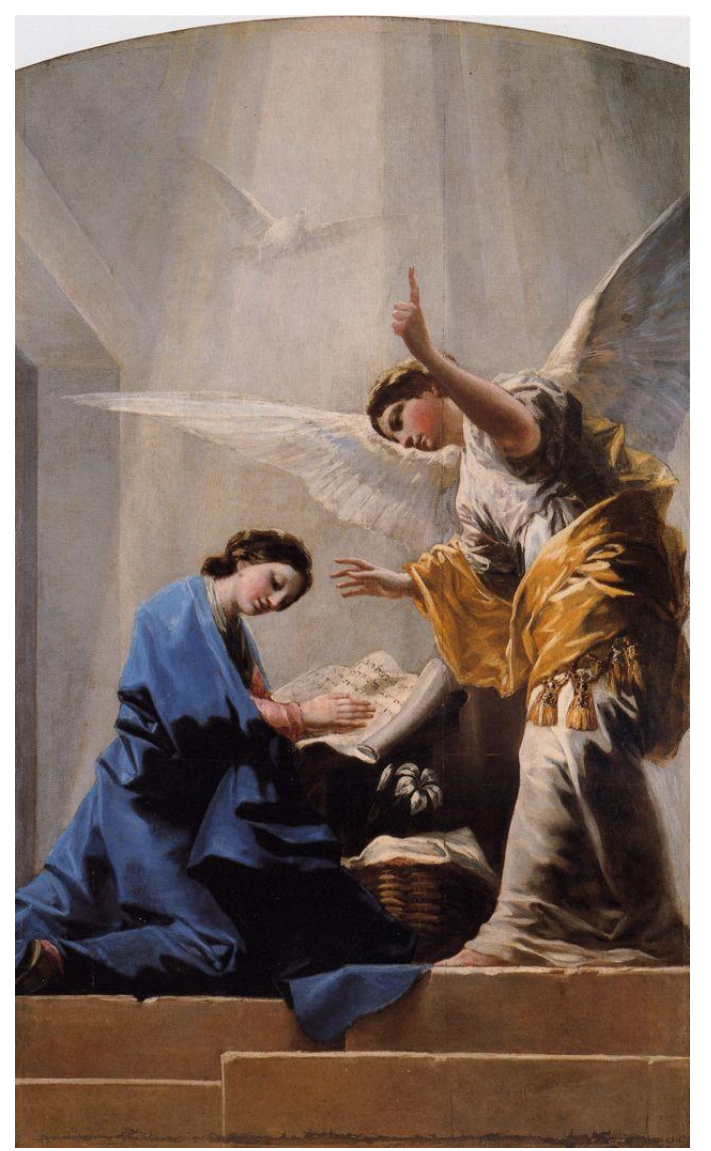

Figure 6. Annunciation - Francisco Goya, 1785

In contrast, the painting of Henry Ossawa Tanner, exhibited in the Philadelphia Museum of Art, and presented in Figure 7 is an unconventional example of an Annunciation, both in terms of composition and of the expressive effect it conveys. Within a highly realistic setting, Tanner presents Mary as an adolescent dressed in modest rumpled Middle Eastern clothing, without a halo or any other holy attributes. The expressive effect is mainly caused by a shaft of yellow light radiating throughout the room and conveying a sensation of heat and awe. The light is produced by a supernatural entity that has taken the place of the canonical Archangel Gabriel, the messenger of the Annunciation. In conceptual terms, Mary seems to convey a combination of FASCINATION and CONCERN. This contrast is visible in the enraptured gaze toward the light and in the dramatic position of the hands. If CLASPED HANDS - especially with open palms - can be associated with PRAYING, but also with SUBMISSION and GRATITUDE, in Tanner's Annunciation Mary's hands are closed, leaning on the legs in what looks more like an expression of CONCERN. 
While in Goya's Annunciation (Figure 6) the CLASPED HANDS were coherent with the bright, quiet and harmonious setting, in Tanner's painting the scene is more dramatic and intimate, expressing not only how Mary's reaction implies faith, but also her concern about the weight of such a responsibility (see Romaine, 2012).

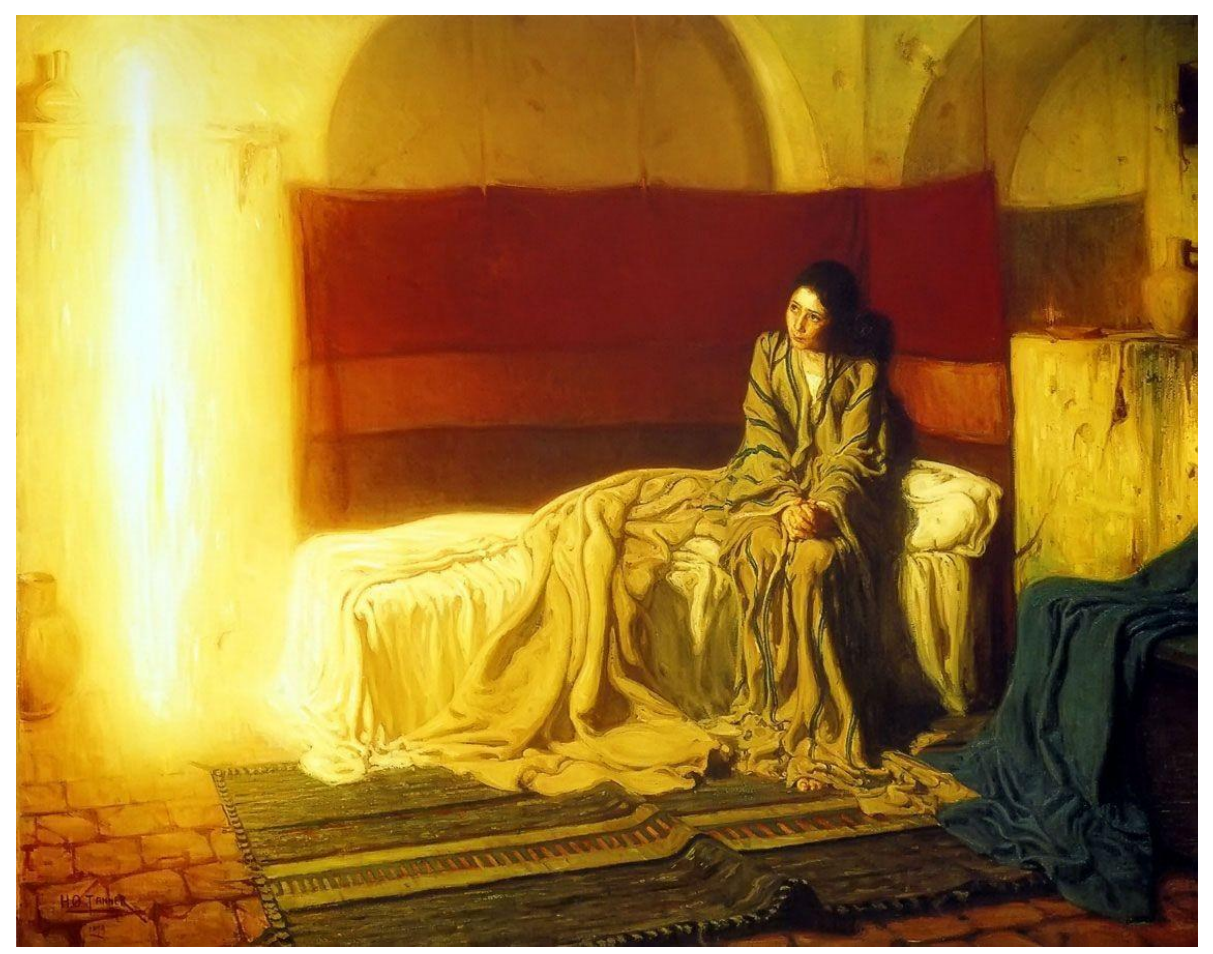

Figure 7. Annunciation - Henry Ossawa Tanner, 1898

The painting by the French artist Luc Oliver Merson shown in Figure 8 is a variation on some of the canonical features that represent the theme of the Annunciation. As shown in the previous paintings, while the archangel usually comes to Mary in a closed space, here he and Mary are both placed in an external setting. In addition, the physical distance between them is generally extremely reduced to highlight the intimacy of the situation in which the Annunciation takes place. In this case, Mary and the angel are at a certain distance from each other, with the Virgin standing in front of the door of her dwelling and the angel looking at her from the top of the roof of a house. Similarly to Tanner's Annunciation, Mary is dressed in modest Middle Eastern clothing and even the external settings look particularly peasant. In conceptual terms, the metaphoric gesture conveyed by Mary assumes great relevance because of its unusual nature. In previous artworks, Mary directly interacts with Gabriel and his message, but in Merson's painting the Virgin approaches the message of the angel by reacting with surprise to a flower - a symbol of the Annunciation itself - that Gabriel has sent to her. In other words, the relationship between Mary and Gabriel is only indirectly established and Mary seems to ignore the messenger since she is raptured by the flower and its symbolic meaning. After seeing the flower, Mary opens her arms in a metaphoric gesture of surprise that also denotes a sense of openness to the Annunciation. In this sense, OPEN ARMS may stand for SURPRISE concerning the unexpected message, but most importantly for ACCEPTANCE of 
the Annunciation. In ordinary English, several phrases convey similar meanings such as "I'm open to changing my mind", "Men and women who extended the arm of generosity" and "My arms are open with love" (Kövecses, 2010, pp. 243-244).

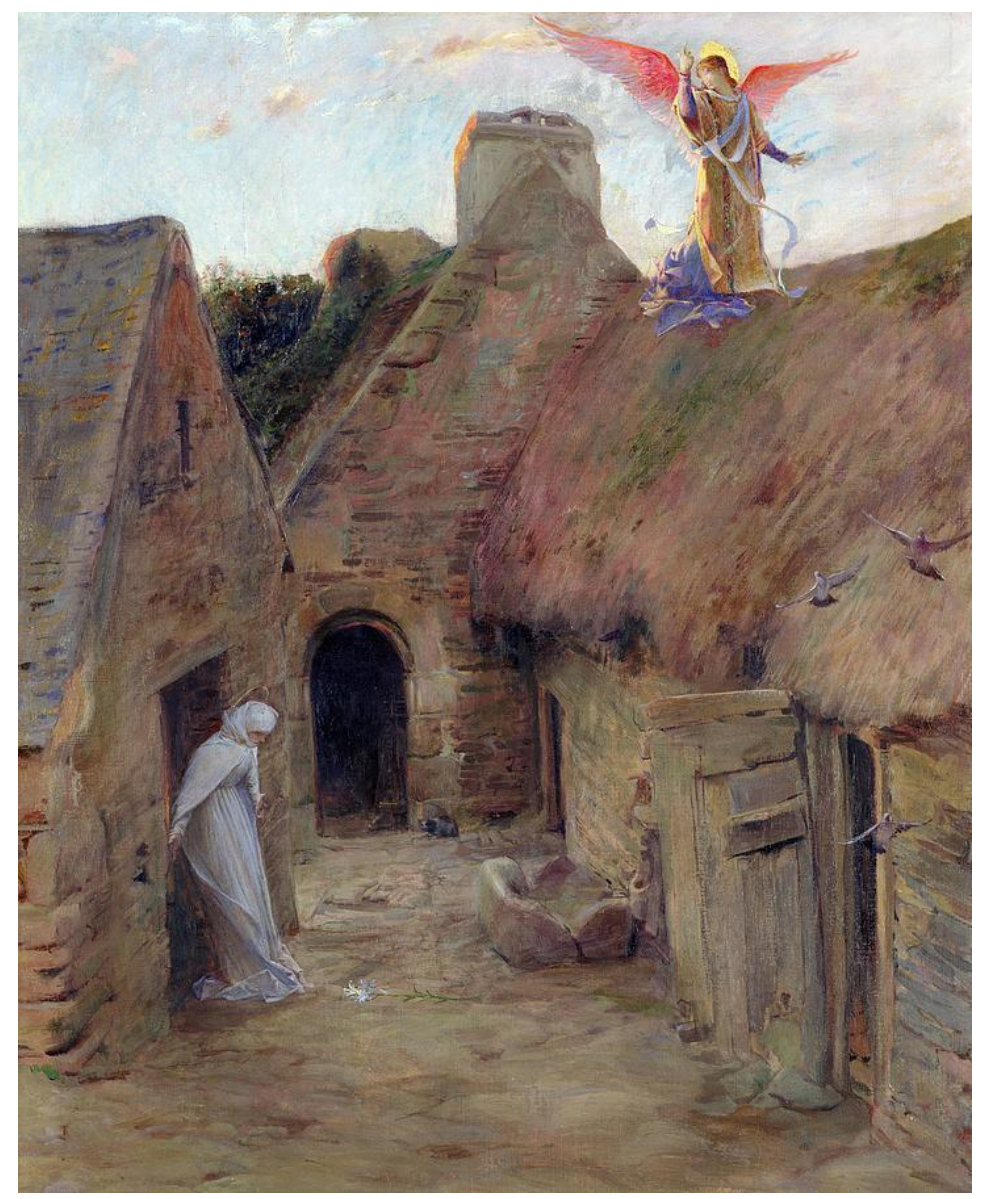

Figure 8. Annunciation - Luc Oliver Merson, 1908

The painting by John William Waterhouse shown in Figure 9 is an example of an Annunciation that combines some of the structural elements conveyed in Merson's painting with some of the most classical elements of the genre. The scene is set in an external rural setting and presents the arrival of the archangel, who surprises Mary in her daily activities. In representational terms, the artwork has at least two non-canonical elements. First, although angels are asexual creatures (Matthew 22: 30), Gabriel is traditionally associated with a male figure; however, in Waterhouse's work the angel takes a more hybrid appearance. Second, while in previous representations Mary expressed symmetrical gestures (e.g. CROSSED ARMS, RAISING THE PALMS, CLASPED HANDS, OPEN ARMS), here the Virgin puts her right hand on her head and her left one on her chest. In terms of metaphoric interpretations, these two hand gestures seem to convey different and contrastive reactions. If HAND ON HER HEAD may be associated with CONFUSION, coming from a sort of rational lack of understanding, Mary's HAND ON CHEST gesture may address a more affective reaction such as EMOTIONAL INVOLVEMENT or GRATITUDE. 


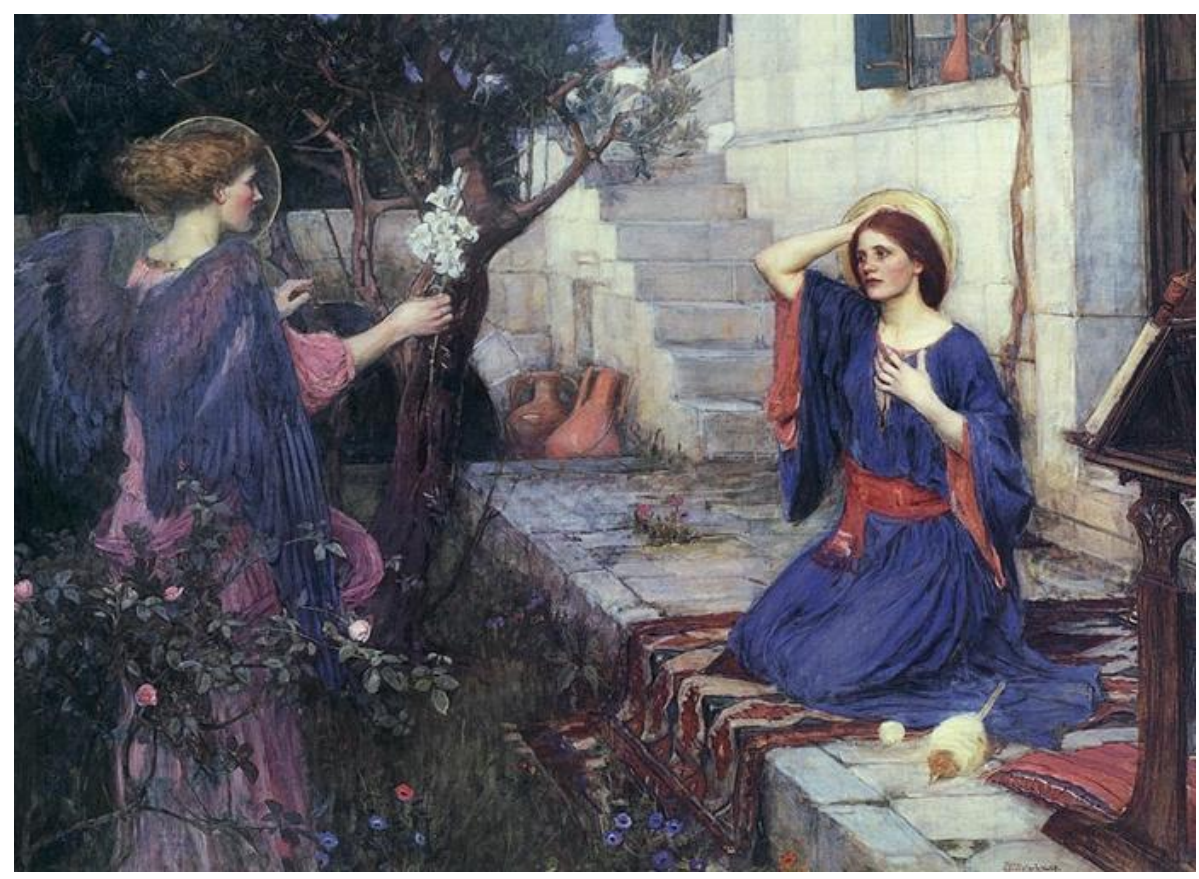

Figure 9. Annunciation - John William Waterhouse, 1914

In our last example in Figure 10, Léon Henri Marie Frédéric presents a version of the Annunciation that puts the setting in the background and focuses entirely on Mary's emotional reaction. While, in previous examples, the space dedicated to the archangel and the Virgin was balanced by the representation of the pictorial context in which the Annunciation takes place, Frédéric's The Painful Annunciation provides a close-up on both figures, with a special emphasis on Mary. Gabriel is portrayed from the back - in line with Caravaggio's tradition - with the index finger of his (or her?) left hand pointing up to God; Mary looks at the flowers that represent a pictorial metaphor of the message. Similar to other examples in which the CLASPED HANDS stand for PRAYING and CONCERN (see Annunciation by Henry Ossawa Tanner, Figure 7), here Mary seems to express a sort of inner pain caused by the responsibility of becoming the mother of God. In contrast with the CLASPED HANDS depicted by Tanner, Mary's hand position looks more dramatic and conflicted, with one of the two hands exerting pressure on the other. Unlike Tanner's painting, the CLASPED HANDS in this scene can be defined as asymmetrical and may be related to a more painful emotional reaction by Mary. Since Frédéric conveyed the idea of pain for the Annunciation even in the title of the painting - in what looks like a unicum in art history - we can claim how ASYMMETRICAL CLASPED HANDS in a metaphoric gesture may represent a DRAMATIC CONCERN rather than a sensation similar to what we have seen in examples such as Tanner's Annunciation. 


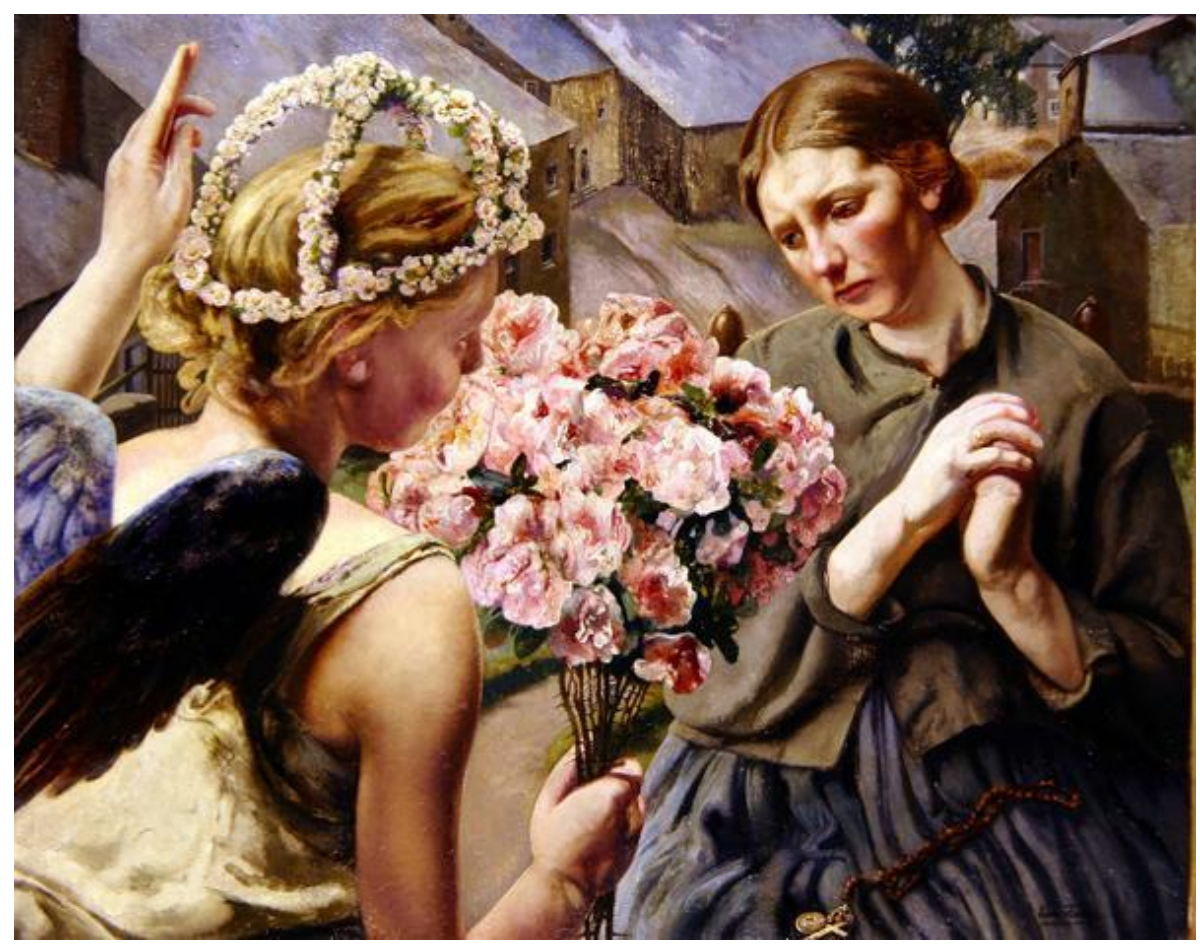

Figure 10. The Painful Annunciation - Léon Henri Marie Frédéric, 1927

\section{Discussion and conclusion}

As our analysis has shown, the ten artistic paintings illustrating the Annunciation present a variety of approaches and representational choices that are associated with some canonical elements persisting across different artistic periods. On the one hand, the structure of the representation of the Annunciation varies throughout the centuries, altering the position of the Virgin and the angel along the horizontal axis (left-right), the setting of the scene, presenting Mary as kneeling, sitting or standing and portraying Gabriel in different ways. On the other hand, the only element that seems to maintain a certain constancy is the role of Mary's hands, as shown again in Figure 11. In the paintings by Caravaggio (Figure 4) and Merson (Figure 8), even the face of the Virgin is not clearly portrayed or is partially hidden by the perspective, while in all the examples we have taken into account, the hand gestures always have a primary importance. The centrality of the hands seems to be based on the capacity that hand gestures may have of being related to several spiritual and emotional states. Although facial expressions may be the primary and most powerful way of expressing similar dynamics (see Tian et al, 2011), the fact that in some examples Mary's face is not able to communicate any further meaning leaves open the possibility that gestures have a similar efficacy. Gestures can be effective in expressing several emotional and spiritual experiences because their varieties allow one to connect a certain feeling to a precise gesture. 


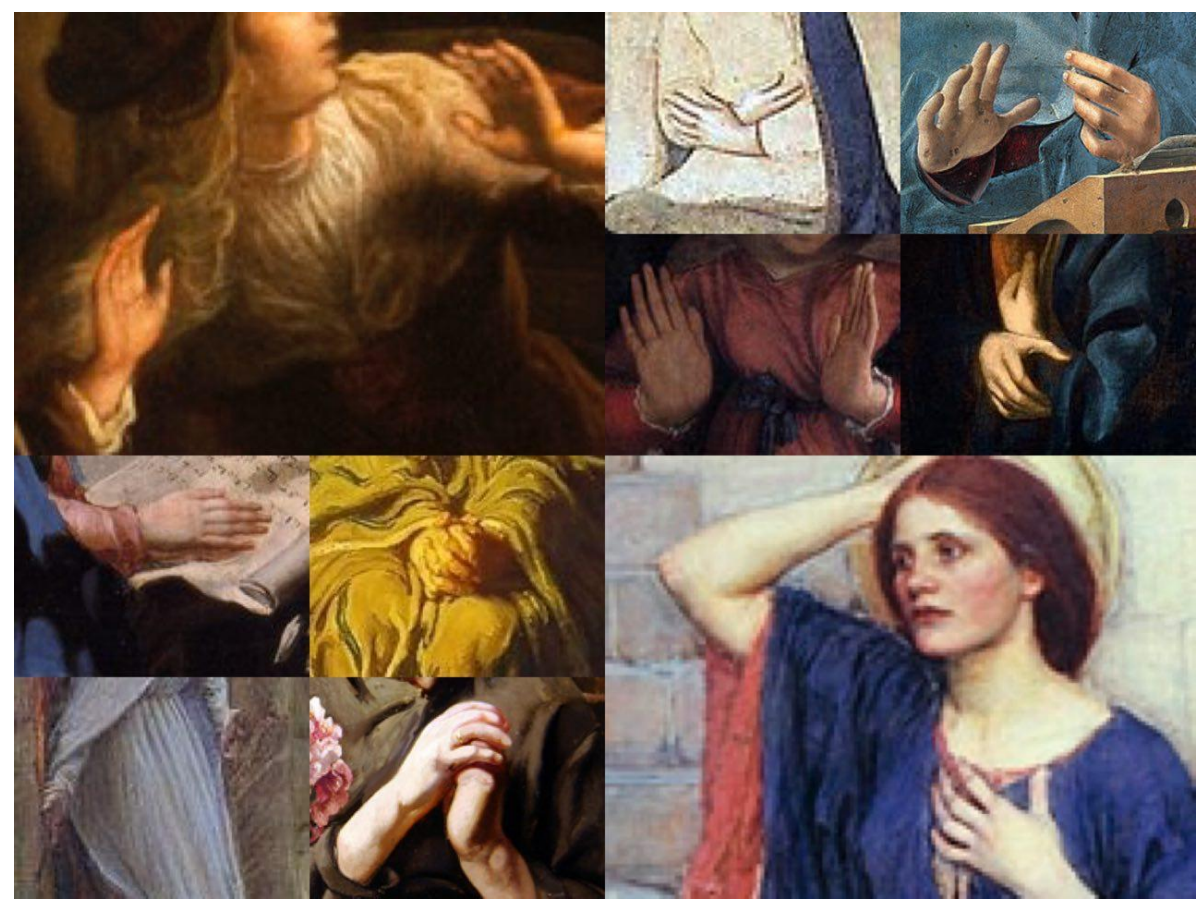

Figure 11. Details of Mary's hand gestures in the ten paintings

In this article, we have analyzed ten artistic paintings of the Annunciation ranging from the XV century to the XX century with focus on the metaphoric gestures expressed by Mary. At the base of this investigation was the need to address how the pictorial representations of gesture carry metaphorical meaning within a non-linguistic modalitiy such as artistic paintings. As we have discussed, we aimed to take a historical approach to pictorial metaphor by discussing which conceptual metaphors are conveyed across different periods by the Annunciation, and to show how two different modalities - such as pictorially represented gesture and other pictorial elements - can interact, producing different conceptual meanings. In methodological terms, the paintings of the Annunciation have been discussed regarding their pictorial metaphors and gesture components, while we have also tried to justify the conceptual relationships by identifying ordinary expressions in English and Italian in order to show how the pictorial and gesture metaphors often have corresponding linguistic metaphors. More specifically, we showed how Gabriel's Annunciation of Mary's destiny to become the mother of God can be associated with dramatic emotions such as PRUDENCE, CAUTION, FEAR, SURPRISE, CONCERN and GRATITUDE, and have suggested how the metaphoric gestures expressed by Mary's hands and arms play a central role in this expression of emotions.

Within our selection of paintings, we have described how the paintings of the Annunciation present a variety of structures and representational choices that tend to change across time. The canonical view of the Annunciation presents the angel on the left, facing the Virgin, who is generally seated or kneeling. However, some of the paintings show variations such as the absence of Gabriel in the representation (Figure 2), a composition that presents the angel in front of Mary (Figure 4 and Figure 10), or behind her (Figure 3). In addition, other variations consider the portrait of Gabriel not in the canonical terms of a young male figure, but as a shaft of yellow light (Figure 7) or as a more feminine 
creature (Figure 9 and Figure 10). Although Mary's facial expressions are sometimes hidden or only partially shown (Figure 8), we have suggested how the only element that seems to maintain a certain constancy is the role of Mary's hands. Despite the different historical sensitivities and the different artistic approaches in the paintings under consideration, the expressive, conceptual power of Mary's hand gestures is generally much more important than that of her facial expressions. Whether hand gestures are universally more effective than facial expressions to communicate spiritual and emotional reactions, is an open question. In any case, even when Mary's facial expressions were hidden (Figure 8), it was possible to infer and justify the relevant interpretation.

As stated, the role of metaphorical gestures in pictorial modalities has rarely been explored, and we claim that our approach has the potential to reveal how metaphorization can simultaneously operate on both the pictorial and the gestural level. While research into metaphorical gesture (see Cienki, 2016a) considers gesture identification within dynamic contexts (e.g., video and animation), we have shown how metaphorical gesture analysis can be addressed within static material such as paintings. In line with Forceville (2007), the relationship between the pictorial and gestural level is triggered by the pictorial context that allows the viewer to understand Mary's gestures in metaphorical terms. In addition, considering that an approach combining the study of metaphor with a historical approach makes it possible to convey some generalizations (e.g., the constancy of the hand gestures), further studies need to explore these conceptual dynamics within larger corpora. In conclusion, the conceptual potential of metaphor may be expressed in pictorially represented gestures interacting with other elements in the pictures and these interactions are so crucial that they play a central role in all the paintings we have analyzed, although they refer to different historical sensitivities and artistic approaches.

\section{Acknowledgements}

The authors would like to thank the anonymous reviewers and the editors for constructive criticism.

\section{References}

Alfieri, L. (2008). Metafora e metonimia: due strutture concettuali, ma quanti processi mentali? In A. Keidan \& L. Alfieri (Eds.), Deissi, riferimento, metafora: questioni classiche di linguistica e filosofia del linguaggio (pp. 1000-1018). Firenze: Firenze University Press.

Alonge, A. (2006). The Italian metaphor database. In Proceedings of the Fifth International Conference on Language Resources and Evaluation (LREC). European Language Resources Association.

Barcelona, A. (2011). Reviewing the properties and prototype structure of metonymy. In R. Benczes, A. Barcelona \& F.J.R. Mendoza (Eds.), Defining Metonymy in Cognitive Linguistics: Towards a Consensus View (pp. 7-60). Amsterdam: John Benjamins.

Barnden, J.A. (2010). Metaphor and metonymy: Making their connections more slippery. Cognitive Linguistics, 21, 1-34. 
Public Journal of Semiotics 8 (1)

Black, M. (1955). XII.-Metaphor. Proceedings of the Aristotelian Society, 55(1), 273294.

Bonnell, V.E. (1997). Iconography of Power: Soviet Political Posters under Lenin and Stalin. Berkeley, CA: University of California Press.

Bounegru, L., \& Forceville, C. (2011). Metaphors in editorial cartoons representing the global financial crisis. Visual Communication, 10(2), 209-229.

Cienki, A., \& Müller, C. (Eds.). (2008). Metaphor and Gesture (vol. 3). Amsterdam: John Benjamins Publishing.

Cienki, A. (2016a). Cognitive Linguistics, gesture studies, and multimodal communication. Cognitive Linguistics, 27(4), 603-618.

Cienki, A. (2016b). Analysing metaphor in gesture. In E. Semino \& Z. Demjén (Eds.), The Routledge Handbook of Metaphor and Language (pp. 131-152). London: Taylor \& Francis.

Coëgnarts, M., \& Kravanja, P. (2012a). Embodied visual meaning: Image schemas in film. Projections, 6(2), 84-101.

Coëgnarts, M., \& Kravanja, P. (2012b). From thought to modality: A theoretical framework for analysing structural-conceptual metaphors and image metaphors in film. Image \& Narrative, 13(1), 96-113.

El Rafaie, E. (2003). Understanding Visual Metaphor: The Example of Newspaper Cartoons in Visual Communication. London: Sage

Forceville, C. (2006). Non-verbal and multimodal metaphor in a cognitivist framework: Agendas for research. Applications of Cognitive Linguistics, 1, 379.

Forceville, C. (2008). Metaphor in pictures and multimodal representations. In R.W. Gibbs, Jr. (Ed.), Cambridge Handbook of Metaphor and Thought (pp. 462-482). Cambridge: Cambridge University Press.

Forceville, C. \& Urios-Aparasi, E. (Eds.). (2009). Multimodal Metaphor. Berlin/New York: Mouton de Gruyter.

Gibbs, R.W., Jr. (Ed.). (2008). The Cambridge Handbook of Metaphor and Thought. Cambrigde: Cambridge University Press.

Goatly, A. (2005). METALUDE: Metaphor at Lingnan University Department of English. http://www.ln.edu.hk/lle/cwd/project01/web/home.html

Grootenboer, H. (2007). Reading the Annunciation. Art History, 30(3), 349-363.

Hanks, P. (2006). Metaphoricity is gradable. In A. Stefanowitsch \& S.Th. Gries (Eds.), Corpus-Based Approaches to Metaphor and Metonymy (pp. 17-35). Berlin: Mouton de Gruyter.

Kappelhoff, H., \& Müller, C. (2011). Embodied meaning construction: Multimodal metaphor and expressive movement in speech, gesture, and feature film. Metaphor and the social world, 1(2), 121-153.

Kövecses, Z. (2010). Metaphor: A Practical Introduction. Oxford: Oxford University Press.

Lakoff, G., \& Johnson, M. (2008). Metaphors We Live By. Chicago: University of Chicago press.

Meier, B.P., Hauser, D.J., Robinson, M.D., Friesen, C.K., \& Schjeldahl, K. (2007). What's "up" with God? Vertical space as a representation of the divine. Journal of personality and social psychology, 93(5), 699.

Musolff, A. (2004). Metaphor and Political Discourse. Basingstoke and New York: Palgrave Macmillan. 
Ortony, A. (1979). Beyond literal similarity. Psychological review, 86(3), 161.

Padgett, J.O. (2006). Ekphrasis, Lorenzo Lotto's Annunciation, and the Hermeneutics of Suspicion. Religion and the Arts, 10(2), 191-218.

Pérez-Sobrino, P. (2016). Multimodal metaphor and metonymy in advertising: A corpusbased account. Metaphor and Symbol, 31(2), 73-90.

Phillips, B.J., \& McQuarrie, E.F. (2004). Beyond visual metaphor: A new typology of visual rhetoric in advertising. Marketing Theory, 4(1-2), 113-136.

Poppi, F.I.M. \& Kravanja, P (in prep.) Sic vita est: Visual representation in painting of the conceptual metaphor LIFE IS A JOURNEY.

Robb, D.M. (1936). The iconography of the Annunciation in the fourteenth and fifteenth Centuries. The Art Bulletin, 18(4), 480-526.

Romaine, J. (2012). Henry Ossawa Tanner: Painting Belief. Art and Christianity, 70, 910.

Schilperoord, J., \& Maes, A. (2009). Visual metaphoric conceptualization in editorial cartoons. Multimodal metaphor, 11, 213-240.

Silvia, P.J., \& Beaty, R.E. (2012). Making creative metaphors: The importance of fluid intelligence for creative thought. Intelligence, 40(4), 343-351.

Tian, Y., Kanade, T., \& Cohn, J.F. (2011). Facial expression recognition. In Handbook of face recognition (pp. 487-519). London: Springer.

Turner, M., \& Fauconnier, G. (2003). Metaphor, metonymy, and binding. In R. Dirven \& R. Pörings (Eds.), Metaphor and Metonymy in Comparison and Contrast (pp. 469487). Berlin \& New York: W. de Gruyter.

Van Mulken, M., Le Pair, R., \& Forceville, C. (2010). The impact of perceived complexity, deviation and comprehension on the appreciation of visual metaphor in advertising across three European countries. Journal of Pragmatics, 42(12), 3418-3430.

Veale, T. (2013). Once more, with feeling! Using creative affective metaphors to express information needs. In M.L. Maher, T. Veale, R. Saunders \& O. Bown (Eds.), Proceedings of the Fourth International Conference on Computational Creativity (pp. 16-23). New South Wales: The University of Sydney.

von Rohr Scaff, S. (2002). The virgin annunciate in Italian art of the late middle ages and renaissance. College Literature, 29(3), 109-123.

Zbikowski, L.M. (2008). Metaphor and music. In R.W Gibbs, Jr. (Ed.), The Cambridge Handbook of Metaphor and Thought (pp. 502-524). Cambridge: Cambridge University Press.

\section{About the authors}

Fabio I. M. Poppi holds a PhD in Linguistics under the supervision of Prof. Andreas Musolff from the University of East Anglia (United Kingdom). His research interests include metaphor, art processing, critical approaches to language and conceptualization, ideology, social cognition and discursive strategies. Many of his projects focus on the relationship between representation and socio-cultural phenomena such as organized crime, political extremism and terrorism.

School of Politics, Philosophy, Language and Communication Studies

University of East Anglia (UEA)

Norwich

United Kingdom

Email: fabioimpoppi@me.com 
Public Journal of Semiotics 8 (1)

Peter Kravanja is a Research Fellow in the research unit of Literature and Culture at the Faculty of Arts, at the Katholieke Universiteit Leuven (Belgium). Mostly in collaboration with Maarten Coëgnarts, he has investigated the interplay between conceptual metaphors and cinema. The results have been published in peer reviewed journals such as Image [\&] Narrative, Projections: The Journal for Movies and Mind, Metaphor and the Social World, New Review of Film and Television Studies, and Metaphor and Symbol. They have also edited the special issue Metaphor, Bodily Meaning, and Cinema of Image [\&] Narrative as well as the book Embodied Cognition and Cinema (Leuven University Press, 2015). More information is available on his website www.kravanja.eu.

Department of Literature and Culture

KU Leuven

Leuven

Belgium

E-mail : peterkravanja@gmail.com 